\title{
THE AMERICAN REFORMATORY PRISON SYSTEM
}

\section{Z. R. BROCKWAY ${ }^{1}$}

The American reformatory prison system is based on the principle of protection in place of punishment; on the principle of the indeterminate sentence instead of the usual time sentence; and on the purpose of rehabilitation of offenders rather than their restraint by intimidation. This theory works a change of attitude on the part of the state, a change of the relation of the offenders, and involves a different prison procedure. Together with punishments by imprisonment every other form of punishment for crimes has, doubtless, to some extent, if vaguely, contained a purpose of protection, yet other aims subversive of protection have unduly influenced criminal legislation and the prison practice: a hateful temper bred of gross superstition attached to the punishments in defense of the gods and to gain their favor; punishment inflicted, assumptively, to equalize the world-balance of diffused morality; to the measuring-out of pains in order to meet some notion of impossible justice; punishments to mend the fractured laws and vindicate the state; to intimidate offenders and the tempted and thus deter from crimes; and, by the sufferings of punishments, to induce a salutary reforming penitence. This hateful spirit, under the name retribution, but with somewhat softened severity, characterized the penitentiary system of the last century. But during the latter half of that century better biological and moral conceptions, largely due to the investigations and publications of Charles Darwin, enabled the enactment of more rational criminal laws. The New York law (I877) eliminates the punishment theory and laws, patterned after it, since enacted in other states, also exclucle the punitive principle.

${ }^{1} \mathrm{Mr}$. Brockway's article forms part of a series of volumes on criminology to be published by the Russell Sage Foundation for the Eighth International Prison Congress which will meet in Washington, D. C., October 2-8, 1910.EDITOR. 
Thus in theory and gradually in fact the attitude of the state is becomingly changed from its former vengefulness to that of dignified serenity, neither vindictive nor lovelorn, but firmly and nobly corrective.

\section{THE MORAL PURPOSE}

It is not attempted, now, either accurately to estimate or, in any direct way, artfully to influence the unrelated inward moral state of the prisoners. It is not denied that idiosyncrasies influence the individual conduct and that these are subject to changes; nor is it doubted that every human impulse and action is, in some way, related to God and the universe of things. But, since the real relation is inscrutable to any but the individual himself within his own variant range of self-consciousness, that relation cannot be deciphered nor properly directed by the legislature, the courts, or by officers of the law. Of course the majority, at any time, may fix the bounds of allowable behavior with due regard to the social welfare, and may erect a standard of socialmoral right and wrong; but, the morality of motives cannot be so determined. Also this criterion of the social demand may itself be reversed or modified by change of time and place and immediate condition; and the very terms Good and Evil are always of capricious significance. "Evils as they are termed are goods to the unjust, and only evils to the just, and goods are truly good to the good but evil to the evil." The effect of conduct does not reliably reveal the real moral motive, for well-intentioned conduct may prove injurious and evil intentions may lead to benefits. Recently one of my former prisoners died after his twenty years of good service and behavior on the editorial staff of a leading metropolitan newspaper. When, as a prisoner, he was compelled to change his daily conduct he at once seized upon the educational advantages at hand to prepare for a notable criminal career. He never suffered any conscious revolution of motive but gradually and imperceptibly his inward intention, rated evil, faded out. Then, like an aeronaut in an unballasted balloon, he floated unconsciously into the higher social and so higher moral altitude. 
None can gainsay Plato's definition that, "he is good whose soul is good.... The virtuous principle is intellectual not emotional or voluntary. . . . . It is knowledge that determines the will." If to this we add Aristotle's criterion of virtue, that, "virtue is a habit accompanied with deliberate preference in the relative mean defined by reason as a prudent man defines," we may accept Lord Bacon's declaration that, "there is no man doeth wrong for the wrong's sake but to purchase for himself a pleasure or profit." In the depths of human action thus fathomed there seems to disappear any trace of intrinsic unrelated morality of conduct.

It is, therefore, a principle of the newer penology that the state shall not judge the heart's intentions, and not judging or knowing, shall not designedly trespass upon the mystical field of the soul's moral relations; but, instead, shall remain devoted to the rational regulation of the prisoner's conduct with sole regard to the public security.

THE PURPOSE OF JUSTICE

Having thus relinquished pursuit of mystic morality because it is deemed impossible correctly to estimate intrinsic moral quality, the pursuit of administrative justice is, for a similar reason, also withdrawn. Justice Fry, who firmly held to the doctrine of just punishment for crimes, admitted that the doctrine takes root "in the endeavor to find a fitness of pain to sin which the world does not satisfactorily supply," and, in his dilemma, advocated that always the greatest conceivable injury of the various crimes should govern the amount of penalty. He would strike offenders hard enough to compensate the greatest possible evil and, so, fully recompense the lesser wrong. This is a vain random reach for justice disregardful of involved severity. Doubtless through all sentient being there exists an instinctive sense named or misnamed justice; but it has a movable interpretation according to the man and the circumstances: it is a chimera in whose name unfair may appear as fair and wrong take on the guise of right. "Divine equity gives to the greater more and to the inferior less (supposedly) in proportion to the nature of 
each." "Justice is always the distribution of natural equity among unequals," but, what human intelligence is sufficient for these things? Our human equity and clemency, esteemed equitable, must infract the strict rule of justice. Notwithstanding the world-wide similarity in terminology of crimes there is great dissimilarity of the penalties attached; and, within the discretionary margin of the laws, different magistrates and the same magistrate at different times fortuitously change the notion of desert and vary penalties. Casual circumstances and personal peculiarities and moods so affect the judgment of men as to preclude uniformity of rule or practice. And so different is the experience of imprisonment upon different prisoners-one's privation another's privilege-that uniformity itself would subvert the intended equality. The blindfold image of justice is most appropriate, for it not only typifies the intended impartiality but also the impossibility for a correct adjustment of the scales.

It is believed that the nearest possible approach to criminal justice is reached unsought-when 'tis left to nature; that "according to the natural order of things, the way of the transgressor is (already) hard;" and, that nature's truest requital for every phase of morbidity-whether of the body, the mind, or the social status-is found in the necessary accompanying pains of the process of recovery.

\section{DETERRENCY}

Little reliance is had on the deterrent principle alone for restraint of crimes or regulation of the conduct and character of offenders. No doubt the experience of pain and pleasure possesses a certain educational value, teaching what is profitable and the reverse; but fear is at best but the beginning of wisdom and fear always evidences and usually effects a reduced and inconstant mental condition. Welfare and adversity, antithetically related, supplement each other, but there is a wide difference of the mood and degree of stability when the one or the other is pursued. Avoiding adversity is as voyaging among reefs and breakers in fear of wreck, while pursuit of welfare is like following the charted ocean path voyaging wide at sea. Strong and 
virtuous characters, well established, do not need and are rarely conscious of amenability to existing penal laws; weak characters easily get themselves enmeshed and stranded; the habitually wayward are unmindful and disregardful of legal penalties; and the small ratio of all the criminals included in the class of deliberate and professional offenders brave penalties and derive zest therefrom.

The bulk of prisoners consists of those who are weak, habitually wayward, and unreflective persons-who do not readily connect, in consciousness, a present infelicitous experience with its remoter cause and consequence. Certainty and celerity of detection and arrest or sudden confrontment with an immediate menacing force may call the halt; but such temporary deterrence cannot effect a permanent change of habitual tendency.

Among the many thousands of this inconsiderate class of prisoners I have investigated none is now recalled to memory who, antecedent to his crime, took serious account of the possible consequences. And a habitual criminal, a fair type of his class, on his discharge remarked: "I mean now to quit, if I get on all right, but not because I am afraid of prison. I am a man who is never afraid." Such men are no more hindered from crimes by the liability to be imprisoned, than railroad travelers are hindered from traveling because there are occasionally fatal railroad accidents. The professional class feels imprisonment to be accidental rather than naturally consequential. One, worrying over his imprisonment because of its interference with his customary associations and excitements, solemnly said: "This is a judgment on me for leaving my own line. So long as I kept steadily at the sneak line I was prospered, but when I tackled burglary my bad luck began."

Ineffective too, for deterrence, is the supposed disgrace of a criminal conviction and committal to prison. The generality of prisoners do not feel any disgrace. A certain tone of respectability colors the prisoner's conception of crime, which is partly a product of his knowledge of current commercial irregularities, corrupt partisan politics, frauds committed in high places with avoidance of convictions, and jubilant newspaper notices of 
crimes and criminals. The very notoriety gained compensates and so shields the shallow characters from any painful feeling of disgrace. His insensibility and sangfroid are further ministered to by the effect of long-delayed trials and the character of the trial; illuminated newspaper detailed accounts of the prisoner's personal appearance and bearing; the gladiatorial show of the legal combat of which the prisoner forms the central figure; the artifice and insincerity of the defense; the excusing and even extolling address of the defending counsel; these together with the chummy attention of jail and court servitors, jail visitors, and salvation seekers, excite the prisoner's self-importance-a new and gratifying consciousness perhaps-displacing the imaginary feeling of disgrace which the inexperienced onlooker himself seems to see. All this show has, too, an evil influence on the common observant crowd. Deterrence is also diminished or destroyed by the previous habitual associations of the average prisoner. In his accustomed haunts, arrests, police-court arraignment, station-house and jail confinement are jokingly mentioned and often considered an interesting personal distinction. Even a color of the heroic tinges the habitue who has actually "done time."

Increased severities either of statutory penalties or conditions of imprisonment cannot evoke and entail a salutary deterrent influence. The history of criminal punishments, the world over, shows the most of crimes accompanying greatest severity and a diminishing volume as mitigation took place. Only transitory effects are produced by severities. The public sense as it becomes familiar rises, in due time, to the new conditions-automatically adjusts itself, thus neutralizing the intended effect. And mere severity of the prison régime reacts upon the prisoners with actual, if unconscious, brutalizing effect with diminishing consciousness of apparent discomfort. Beyond the possible temporary stimulation of alternative pain and pleasure experiences, deterrent measures are disused and the deterrent principle itself is disesteemed. 


\section{ALTRUISM}

That phase of altruism which, in exercise, holds benevolence to others in subordination to self-interest is dominantly present in our prison system. This altruistic sentiment exists in the protective purpose of the law which establishes it, pervades the administrative polity in all its details, and gains impulse with its sympathetic reward in individual reclamations achieved. But in its active agency the principle is a rational characteristic, not a mere sentimentalism. It is devoted to prompt enduring welfare rather than passing enjoyments. The paramount object always in view is a collective benefit sought and wrought through the well-being of individuals, and the individual welfare through a better adjustment to ordinary communal relations. In use and inculcation it is ego-altruism, for the personified state seeks her own advantage, and the prisoners pursue, whether voluntarily or compulsorily, their own advancement. The benefits are mutual-an increase of ultimate mutual abiding happiness. The principle of the New York law, as of the other laws patterned after it, notwithstanding their marring limitations, constitutes a radical change of spirit in criminal jurisprudence. A distinguished jurist has publicly declared that the change "is destined to change men's habits of thought concerning crime and the attitude of society toward criminals; to rewrite from end to end every penal code in christendom; and to modify and ennoble the fundamental law of every state." It is a change from a plane, where feeling sways, to the loftier realm and reign of wisdom. It is conceded that no human agency can operate quite free from emotional influence, but the emotions are always a dangerous element in law-making and governing. To this vitiating source is traced the undue severities of all time, and, also, the supersentimentality which now is, perhaps, the most serious menace of our prison system. The true is a restrained and rational altruism - a brooding beneficence, impartial, and ever striving to promote the interdependent collective and individual welfare subordinating, as needs be, transitory pleasure to the more permanent and the nobler good. 
The attitudinal relation of the state to our prison system is thus shown to be: negative as to any punitive intention; negative as to administering exact justice for its own sake; negative as to the expectation of deterrence by intimidation; neutral as to regulating the mystical individual moral relations of prisoners; and a qualified attitude as to altruism. The state's affirmative attitude will subsequently casually appear.

\section{CHANGED RELATION OF PRISONERS}

This better, attitude on the part of the organized state effects also a corresponding change of the relation of offenders toward the state. The change is real, though, for a time, it may not be prized by the prisoners or noticed by the administering authorities. Formerly, the fundamental relation was antagonisticnecessarily so for, under the definite-sentence plan the everpresent desire for release must be opposed by the prison government until expiration of the prescribed period of time. Now, under the new form of prison sentence, the desires of both parties are in accord-the prisoner wants to go and the government wishes the same; but only upon certain conditions. Here contradiction is likely to arise, but it soon of itself disappears, as regards the majority of prisoners, and the remainder of them, when they discern the peaceable fruits of the opposition, change to an accordance, which is often succeeded by a pleasing gratitude. While an outside observer might never note this changed relation by any change in the general appearance it actually exists.

It is essentially the principle, "community of interest," which is the germinal basis of most of human concord. Its well-nigh magical effect is seen in states held in union under federal control; civil divisions of states bound in fealty to each other and the state government; communities made orderly; family integrity preserved; and it is seen in enduring common friendships of individuals. The inner shrine of community of interest is of course self-interest but grown large enough to observe its outward dependence. Whenever self-interest is so wisely directed that self-indulgence is self-restrained in the interest of remoter 
better benefits; when individual consciousness enlarges to "colonial consciousness;" when the principle of interdependency dawns, then is born that mutuality which is indestructible and socially most desirable.

As to the "criminaloid" class distributed through communities it is not expected that any striking demonstration or formal statistics shall soon reveal a decided change of attitude. But, with the certainty of cause and effect, improvement in tone and probity must occur in response to the new spirit of the criminal laws; the new purpose of the courts and court procedure; and to the renovated, more rational state-prison system; for to effect such changes necessitates a change in the general public sentiment, at once the final arbiter and most powerful molding social force.

\section{AFFIRMATIVE PRINCIPLES}

Under the indeterminate sentence it is intended, either by restraints or reformations, that prisoners once committed to our prisons shall then and thereafter be permanently withdrawn from the ranks of offenders. And the inherent evils of imprisonment are such that only genuine reformations can afford the intended protection.

\section{STANDARD AND CRITERION}

To accomplish such protective reformations it is necessary, preliminarily, to fix upon the standard of reformatory requirement, to adopt the criterion, to organize and perfect the plan of procedure. The standard fixed is, simply, such habitual behavior, during actual and constructive custody, as fairly comports with the legitimate conduct of the orderly free social class to which the prisoner properly belongs in the community where he should and probably will dwell. The criterion of fitness for release is precisely the same performance subjected to tests while under prison tutelage by the merit and demerit marking system which somewhat modified in strenuousness and with addition of its monetary valuations is similar to the marking system of our National Military Academy; and tested, also, by proper super- 
vision during a period of practical freedom while on parole. Both the standard and criterion must be somewhat pliant to meet the variant capacity of communities to absorb incongruent elements and because each prisoner must be fitted for his appropriate industrial and social niche.

\section{THE DEFECTIVENESS OF PRISONERS}

It cannot too often be stated that prisoners are of inferior class and that our prison system is intended for treatment of defectives. Passing now the somatic, psychic, and other anthropological data at hand in support of the above statement; premising that the defectiveness is of the bodily substance and form; in the mental capacity and its irregularity; and in emotional perversity, the aggregate of which in any large company of miscellaneous prisoners is always in excess of the defectiveness of the same number of free inhabitants, the inferiority of prisoners may, for the present convenience, be generalized under three divisions as follows:

I. Those who, in childhood and adolescence, are apparently normal, but closely scanned reveal peculiarities which resulting in pernicious habits and crimes develop later into some phase and degree of dementia.

2. Those clearly defective but with considerable normal mental power preserved. The mental defect is specific, in some one particular, such as the logical faculty. For instance, they are unable to master arithmetical examples which others of similar general intelligence easily grasp-they are deficient in judgment rather than depraved. At every trying crisis of life they are sure to "go wrong."

3. Those possessed of all the usual faculties except the regulative one which is out of gear-not absent but disconnected and unavailable.

At the Elmira Reformatory when such inquiries were most searchingly made, it was discovered that out of the total inferior mass, numbering fifteen hundred men, five hundred of them were so very defective that they were temporarily withdrawn from the regular reformatory routine and were subjected to 
special renovating and stimulating treatment in order to bring them up to the standard of regular training.

Viewed en masse, prisoners are characterless, they lack positiveness, are without an inward dominant purpose. They are unduly influenced by instant, trivial circumstances, or by hidden transient impulses. The most dangerous, therefore interesting, sane young prisoner I have ever known, abnormally cunning, well illustrates this ungeared characteristic. He said: "I know, sometimes, I am what you call good and then again bad. In my good moods I am ashamed that I was ever bad; and equally in the bad mood I am ashamed of ever being good." His alternate self-disapprobation had no content of intellectual stability or moral responsibility. Although he was only eighteen years old, he was by heredity and habit a confirmed and desperate criminal. Fortunately he died while imprisoned.

Morbidity of body, mind, or the moral sense diminishes individual industrial efficiency and in turn narrows opportunity; leading on to indolence, privations, dissipation, and crimes. The source is held to be in physiological defects; the declaration of Ribot and other eminent psychologists is credited as true that: "The character is but the psychological expression of a certain organized body drawing from it its peculiar coloring, its special tone, its relative permanence." The nature and the habit of living matter must exert so powerful influence upon volition that the conception of the individual will dominating and unaffected by constituents and conditions of the total personality is deemed no longer tenable. On the contrary it is confidently believed that, quite independent of the immediate conscious choice and will of the prisoner, agencies foreign to himself may be made effective to change his character; that the material living substance of being is malleable under the simultaneous reciprocate play of scientifically directed bodily and mental exercises; and that the agencies are irresistible.

The doctrine of the interaction of body and mind is so well established and altogether reasonable that there is no need here to guard against a fancied materialistic tendency. Rather there is occasion to guard against too fanciful idealism. There may 
be a grain of truth in the remark of George Eliot: "In proportion as the thoughts of men are removed from the earth in which they live to an invisible world they are led to neglect their duty to each other." Dr. E. H. Hartwell says: "Bodily actions demand our first consideration since without them mental power, artistic feeling, and spiritual insight cannot be made to answer any earthly purpose." To this extent the principle of determinism is espoused; and unhesitatingly, alleged free will is invaded. By rational procedure the social in place of anti-social tendencies are trained and made dominant. Thus the man is redeemed.

\section{ORGANIZATION AND CONTROL}

The original and preferable principle for organizing our reformatories is that of local-centralism. The state legislative control should be limited to a broadly outlined enabling act in harmony, of course, with the general state penological policy, but leaving much freedom of initiative to the local institutional authority-the board of managers. This local authority, in turn, had best limit its functions to fixing, changing, and supervising the administrative polity, leaving the immediate executive management to the resident chief officer-the prison governor. The governing principle of a reformatory must needs be, within certain constituted rights, of monarchial type, but exercised with much discretionary flexibility; approximately as a community under martial law, where both civic and military functions obtain. Such a blend is practicable and useful; indeed it is requisite.

It is important that the subordinate staff shall remain subordinate; that each officer and employee shall confine his reformative activity to his own assigned specific duties. The chiefs of the several departments may properly constitute a coterie for the study of prison science, for consultations and advisings, but they should each act entirely within his own particular sphere and under authoritative direction. And the rank and file of the staff should remain as the soldier, and never independently assume the rôle of the reformer. No outside training school for prison officers can ever supply a suitable reformatory prison 
staff. Both the selection and training of assistants is best when controlled by the governing head of each reformatory. The civil-service system wards off some improper demands for appointments but at the same time restricts the range of selection and hinders prompt sifting-out of the unfit. Its serviceableness, however, preponderates.

So delicate and easily disturbed is the generative reformative process that outsiders-the would-be special philanthropists, professional religious revivalists, advertising salvationists-should generally be excluded; or if at all admitted to any participation, their ministrations should, under the direction of the governor, be made to fit into the established culture course. Even a resident official chaplain may inadvertently interfere with the germination of reformations. I have found the resident chaplain to be less desirable for religious ministrations than an itinerant service. One mind, and that the mind of the resident reformatory governor, must have and hold and yield every operating agencyimpel, steady, and direct the whole and every item of the procedure. Such completeness of control requires an exacting and strenuous disciplinary régime which for effectiveness must include the principle and exercise of coercion.

A majority of prisoners instinctively respond to the inherent persuasion of the combined agencies; and of those who do not a majority readily respond to the moral coerciveness of the agencies. Some, only a small ratio, do not respond at first, except to some form of corporal coercion-some bodily inconvenience and discomfort. These, the irresponsive, who, for the good of the prison community and for the public safety most need reformation, should not be neglected nor relegated to incorrigibility until every possible effort has unavailingly been made for their recovery. The advantages proffered are, naturally, not appreciated until availed of and enjoyed. Some cannot adopt and carry into execution measures calculated for their own good without the intervention of coercion. Adjustment to environment, even if it is compulsory, leads from the avoidance of bodily risks to the avoidance of social risks and thus to non-criminal habits, which, when duly formed, no longer need the prop of 
compulsion. "Compulsion first, then the sense of duty, automatic, the connection expanding into knowledge of ethical habit, then the habit creating conviction, then relations, then the capacity for general ideas." Thus coercion is often of initial indispensable educational value. Not infrequently prisoners who were assisted out of a stalled condition by means of an applied physical shock have expressed to the managers their grateful acknowledgments therefor. Many such prisoners who without the physical treatment would have remained long in the ranks of the incorrigible have, after the simple treatment, developed well and ultimately established themselves in the confidence of their community as reliable, useful inhabitants.

There should be within the reformatory course a reserve of penological surgery similar in beneficent design and in scientific use to the minor surgery of the healing art of medicine.

\section{THE PROCEDURE}

\section{THE MECHANIŠM OF MEANS AND MOTIVES}

Efficiency of the reformatory procedure depends on completeness of its mechanism composed of means and motives; on the force, balance, and skill with which the means and motives are brought to bear upon the mass, the groups, and the individual prisoners; and not a little on the pervading tone of the reformatory establishment. A mere enumeration of means and motives of the mechanism is, briefly, as follows :

I. The material structural establishment itself. This should be salubriously situated and, preferably, in a suburban locality. The general plan and arrangements should be that of the "Auburn" Prison System plan but modified and modernized as at the Elmira Reformatory; and Io per cent. of the cells might well be constructed like those in the Pennsylvania System structures. The whole should be supplied with suitable modern sanitary appliances and with abundance of natural and artificial light.

2. Clothing for the prisoners, not degradingly distinctive but uniform, yet fitly representing the respective grades or standing of the prisoners. Similarly as to the supply of bedding which, 
with rare exceptions, should include sheets and pillow slips. For the sake of health, self-respect, and the cultural influence of the general appearance, scrupulous cleanliness should be maintained and the prisoners kept appropriately groomed.

3. A liberal prison dietary designed to promote vigor. Deprivation of food, by a general regulation, for a penal purpose, is deprecated; and is a practice only tolerable in very exceptional instances as a tentative prison disciplinary measure. On the other hand, the giving of food privileges for favor or in return for some special serviceableness rendered to the prison authorities is unadvisable and usually becomes a troublesome precedent. More variety, better quality and service of foods for the higher grades of prisoners is serviceably allowable even to the extent of the à la carte method, whenever the prisoners, under the wage system, have the requisite credit balance for such expenditure. Also, for some of the very lowest intractable prisoners, a special, scientifically adjusted dietary, with reference to the constituent nutritive quality, and as to quantities and manner of serving, may be used to lay a foundation for their improvement otherwise unattainable.

4. All the modern appliances for scientific physical culture: a gymnasium completely equipped with baths and apparatus; and facilities for field athletics. On their first admission to the reformatory all are assigned to the gymnasium to be examined, renovated, and quickened; the more defective of them are longer detained, and the decadents are held under this physical treatment until the intended effect is accomplished. When the population of the Elmira Reformatory was I,400, the daily attendance at the gymnasium averaged 429 .

5. Facilities for special manual training sufficient for about one-third of the resident population. The aim is to aid educational advancement in the trades and school of letters. This special manual training, which at Elmira reformatory included, at one time, five hundred of the prisoners, the training given in addition to other exercises in other departments covered mechanical and freehand drawing; sloyd in wood and metals; 
cardboard constructive form work; clay modeling; cabinet making; chipping and filing; and iron molding.

6. Trades instruction based on the needs and capacities of individual prisoners, conducted to a standard of perfect work and speed performance that insures the usual wage value to their services. When there are a thousand or more prisoners confined, thirty-six trades and branches of trades may be usefully taught.

7. A regimental military organization of the prisoners with a band of music, swords for officers, and dummy guns for the rank and file of prisoners. The military membership should include all the ablebodied prisoners and all available citizens of the employees. The regular army tactics, drill, and daily dress parade should be observed.

8. School of letters with a curriculum that reaches from an adaptation of the kindergarten, and an elementary class in the English language for foreigners unacquainted with it, through various school grades up to the usual high-school course; and, in addition, special classes in college subjects and, limitedly, a popular lecture course touching biography, history, literature, ethics with somewhat of science and philosophy.

9. A well-selected library for circulation, consultation, and, under proper supervision, for occasional semi-social use. The reading-room may be made available for worthy anđ appreciative prisoners.

Io. The weekly institutional newspaper, in lieu of all outside newspapers, edited and printed by the prisoners under due censorship.

I I. Recreating and diverting entertainments for the mass of the population, provided in the great auditorium; not any vaudeville nor minstrel shows, but of such a class as the middle cultured people of a community would enjoy; stereoptical instructive exhibitions and explanations, vocal and instrumental musical occasions, and use of elocutionary, recitatory, and oratorical notables for inspiration and uplift.

I2. Religious opportunities, optional, adapted to the hereditary, habitual and preferable denominational predilection of the individual prisoners. 
I3. Definitely planned, delicately directed, refreshing, emotional rare occasions; not summoned, primarily, for either instruction, diversion, nor, specifically, for a common religious impression-but, figuratively, for a kind of irrigation. As a descending mountain torrent may irrigate and fertilize an arid plain, scour out the new channels, and change even the physical aspect, so emotional excitation may inundate the human personality with dangerous and deforming effect if misdirected; but when skilfully handled it may work salutary changes in consciousness, in character, and in that which is commonly thought to be the Will. Esthetic delight verges on and enkindles the ethical sense, and ethical admiration tends to worthy adoration. The arts, which in essence are the external expression of the idea - the revelation of the reality-have too exclusively remained the heritage of the wealthy and wise, must ultimately fulfil their God-given design-ennoblement of the common people. "We shall come upon the great canon-'art for man's sake' instead of the little canon 'art for art's sake." " I have sufficiently experimented with music, pictures, and the drama, in aid of our rational reformatory endeavors, to affirm confidently that art may become an effective means in the scheme for reformations.

In addition to the foregoing items the prisoners are constantly under pressure of intense motives that bear directly upon the mind. The indeterminateness of the sentence breeds discontent, broods purposefulness, and prompts to new exertion. Captivity, always irksome, is now increasingly so because of the uncertainty of its duration; because the duty and responsibility of shortening it and of modifying any undesirable present condition of it devolves upon the prisoner himself, and, again, by the active exactions of the standard and criterion to which he must attain.

Naturally these circumstances serve to arouse and rivet the attention upon the many matters of the daily conduct which so affects the rate of progress toward the coveted release. Such vigilance, so devoted, supplies a motive equivalent to that of the fixed idea. Then the vicissitudes of the daily experience incite to prudence; and the practice of prudence educates the understanding. Enlightenment thus acquired opens to. view the attract- 
ive vista where truth and fairness dwell. Habitual careful attention with accompanying expectancy and appropriate exertion and resultant clarified vision constitute a habitus not consistent with criminal tendencies.

\section{BALANCE, SKILL, AND TONE}

At present, owing to absence of exact knowledge of the modes of the mutual dependence of mind and body, it is not possible to wield, with perfect balance, the contingent means and motives, nor accurately adjust the operation of the scheduled elements of the joint composition-the total mechanism. But the fact of interdependence is so well established and so much of the method has been learned from experiment that the principles of mental physiology or physiological psychology should be applied in the reformatory procedure. It is uniformly conceded that the nervous system, concentered in the brain, is the organ or instrument of the mind; that the mind is a real being which can be acted upon by the brain and which can act in the body through the brain. For the sake of the authority and simplicity of statement of this elementary biological truth I quote from Professor Ladd as follows:

The mind behaves as it does because of the constitution and behavior of the molecules of the brain; and the brains behave as they do behave because of the nature and activities of the mind. Each acts in view of the other. The action of each accounts for the other..... The physical process consists in the action of the appropriate modes of physical energy upon the nervous and end-apparatus of sense, . . . . brought to bear through mechanical contrivances carrying impulses to the mind. And psychical energies are transmuted into physiological processes-a nerve commotion within the nervous system thence propagated along the tracks and diffusing over the various areas of the nervous system.

This brief statement of the dual human constitution, the condition of whose changeable and changing elements at any time so determines conduct, points to the possibility and so to the duty of effecting salutary alterations in the personality of prisoners by means of skilfully directed exercises of mind and body in harmonious mutual conjunction. If there exists a spiritual reality, neither brain nor mind, which manifests itself 
in both, it is beyond our ken and the fact need not divert or hinder from rational efforts. For surely the best expression of such a force must be had when the mind and body are best conditioned. Doubtless changes of personality are easier accomplished in the period of childhood and youth, but throughout the entire conscious life of a man there is no period when the citadel of the personality may not be taken by suitable siege.

A skilful, successful siege, while it encompasses the mass, must also reach to the groups and individual prisoners ministering with much particularity. This is practicable, even with the largest prison population. It is observed that the police prefecture of a municipality may know and influence the conduct of every inhabitant; that the "organization" of a political party knows the distinctive character of each elector and the agency effective to influence his political action; that at our National Military Academy the marking system reveals the idiosyncrasy of each cadet and is reliable data for forecasting his career. In like manner the governing authority of a reformatory may and should have knowledge of each prisoner and, definitely, the use and effect of agencies directed for his advancement.

Such particularity is facilitated by group formations, great and small, composed of prisoners whose similar characteristics permit their treatment in group connection. In order to meet the several similarities the groups will form and reform and change kaleidoscopically, but always with prescribed order and precision of selections, so that in the round of groupings the special needs of each are duly treated. Fully a hundred such groups existed at the Elmira Reformatory within a general prison population of fifteen hundred, and the individualism helped to solidify and at the same time steady the mass to stand the necessary strain of the effective disciplinary régime then in vogue.

The words "necessary strain" are used advisedly. Stringency and strenuosity are indispensable principles of administration. Lax, superficial, or perfunctory administration easily transmutes the intended reformatory into a damaging instrument producing deformities instead. Strictness and strenuousness serve also to counteract any possible injurious attractiveness of the unusual 
cultural opportunities and privileges the reformatory system involves. Not only a solidifying and steadying effect is wrought, but at the same time the irresponsive prisoners are sifted out and settled to their appropriate place.

Every separate reformatory institution has its own particular tone, derived originally from the central controlling individual, fed, fanned, and reflexively disseminated. This institutional tone is an impalpable something which, like the consensus of a public opinion, is always a powerful determining factor. As the hundred instrumentists of a great orchestra reach their highest excellence by inspiration of their leader so the most effective reformatory work must have its tone of inspiration. It is the product of a quality rather than of external influences. Important as it is that the governing head should do and say the wisest things, it is of vastly more importance that he possess within himself the manly qualities and glowing interest which, when generally communicated, insure the best success. Such inwardness is self-propagative.

With the utmost of confidence in the category of principles arrayed, and supplied with the completest reformatory mechanism, yet, when confronted with the duty to effect reformations, so lofty and complex is the problem, so delicate are the processes, and so much is the skill required, that it is not surprising if incredulity should arise. But when the problem is resolved into two essential elements it seems more simple. These elements are the formation of desirable habitudes, and development of individual economic efficiency.

HABIT

The only useful knowledge we can have of the springs of character is to be derived from intelligent observation and true interpretation of the customary behavior. That every individual has characteristics fixed in his innate constitution or nature-a certain temperament and natural tendencies-cannot be denied. But external circumstances have already somewhat modified the original characteristics; and none can name the limit of further possible modifications to be effected by different circum- 
stances and very different customary conduct. While the force of the original nature should not be utterly disregarded, and some regard must be had to the influence of exceptional flowering reason, new dominating tendencies like an acquired or second nature may be created.

Nature-custom-reason: the greatest of these is custom. Criminal behavior may but express a want of regulated channels for the flow of vital force or lack of force. As the stagnant pools of a barren rivulet exhale malaria, and, as the freshet serves to spread pollution, so a low rate of vitality may account for vagrant impulses, and, when under even normal pressure, insufficiency or irregularity of ducts of habit may produce pernicious conduct. Habit is formed by practice. By practice new nervous paths are made and connected. Movements of body and mind become more and more under conscious direction of the subject-from mere automatism through various stages until permanent change is wrought. Repeated efforts and movements which tend to produce right habits and, at the same time, disuse of every unsuitable activity may become so fixed in the constitution that when any spring of action is touched, desirable action will follow and with reasonable certainty of result as a consequence of collaborated forces of mind and body. The degree of perfection of habit may be fairly estimated by the promptness and uniformity of the action responsive to the stimulus.

A signally distinguishing characteristic of the American Reformatory Prison System is the importance attached and the attention given to methodical treatment of the material organism for renovation-mayhap a little of refining effect and adjustment of sense to mind. Such physical training is believed to be a rational basal principle of reformatory procedure.

\section{ECONOMICS}

Another distinguishing feature, still more important because it is the germinal, all-embracing principle from which every progress proceeds, is the use of the economic motive and training to thriftiness. This principle which is inherent in human nature and in the nature of things, plainly written in history, manifest 
in current affairs, present in every normal consciousness, the ground principle so long obscured from our educational systems and religious observances by reason of mediaevalism and institutionalism, so blurred in our common life by excess and artifice, so misused in prison labor systems, is now rallied for its appropriate use in the scheme for reforming prisoners.

Successful legitimate industrial performance involves native or acquired capacity and disposition for useful work. This in turn demands such development of physical energy that exertion is pleasurable or not painful; it requires a degree of mechanical and mental integrity which verges on morality and, indeed, is of the same essential quality; there must be sufficient dexterity for competitions, and stability equivalent to reliability that insures a commercial value to the services. It is the observation of experience that such an effect can be produced by industrial training; and, moreover, the possession of means, produced by exercise of the honest qualities made necessary to successful labor, conveys to the workmen a stimulus as of achievement, the ennoblement of proprietorship, and suggests some sense of solidarity of interests which prompts to prudence, thence to proper fraternity of feeling and conduct. After such a course of training and actual achievement, when the prisoner is sent out, on conditional release, to the situation arranged for him, possessed of his self-earned outfit of clothing, tools, and money, having left behind a margin of his savings to be added to from time to time or drawn upon to meet exigencies; after his sustained test on parole under the common circumstances of free inhabitancy, is he not, ordinarily, entitled to reasonable confidence that he will live and remain within the requirements of the laws?

The formation of such a new social habitude is an educational, therefore a gradual, process which requires time as well as practice. Whatever of real value may attend the preaching of disinterested benevolence to the outside general inhabitants, it is, as an independent agency, of little use for a community of common convicts. Such of them as might be moved by such an appeal are, usually, scarcely normal, and their responsive benevo- 
lent acts are likely to be injurious. Fellow-feeling for comrades may prompt to crimes, collusions, and public disorder.

The same may, properly, be said of prescriptive moral maxims, generally, and of the possible effects of personal entreaty. Also effort, such as is commonly made to induce a habit of moral introspection, is believed to be a mistaken policy. The state standard of practical reformations is not the product of inward moral contrition; more naturally contrition is consequent on reformation. When reformation is accomplished contrition is useless and often harmful. It was deemed not an encouraging indication when, as occasionally happened, a prisoner on his admission to the reformatory, answering interrogatories, flippantly said: "I am going to reform;" not encouraging, because it showed no real purpose or some vague diverting notion of reformation quite aside from the real thing. The most hopeful response was felt to be when a desire was expressed or felt to learn some trade or income-giving occupation.

Moral suasion and religion are recognized as reformative agencies in our prison system, but no particular niche is prescribed for them such as is assigned to other agencies. Moral tone and the religious consciousness are a flavoring quality immediately penetrative. It is a savory attribute inherent in and emanative from the humblest as the noblest effort and exercise intended for any betterment.

\section{CONCLUSION}

Neither punishment nor precept nor both combined constitute the main reliance; but, instead, education by practice--education of the whole man, his capacity, his habits, and tastes, by a rational procedure whose central motive and law of development is found in the industrial economies.

This is a reversal of the usual contemplative order of effort for reformations-the building of character from the top down, to the modern method which builds from the bottom upward, and the substratum of the structure rests on work.

This better order of procedure is in accord with the method of human development foreshadowed by the allegorical scriptural 
Eden episode; and it does not preclude the highest aim and attainment. The far-reaching reformatory possibilities of work are admirably pointed out by Professor Drummond. I quote:

Work is an incarnation of the unseen. In this loom man's soul is made. There is a subtle machinery behind it all, working while he is working, making or unmaking the unseen in him. Integrity, thoroughness, honesty, accuracy, conscientiousness, faithfulness, patience-these unseen things which complete a soul are woven into the work. Apart from work these things are not. As the conductor leads into our nerves the invisible force, so work conducts into our spirit all high forces of character, all essential qualities of life, truth in the inward parts. Ledgers and lexicons, business letters, domestic duties, striking of bargains, writing of examinations, handling of tools-these are the conductors of the Eternal! So much so that without them there is no Eternal. No man dreams integrity, accuracy, and so on. These things require their wire as much as electricity. The spiritual fluids and the electric fluids are under the same law; and messages of grace come along the lines of honest work to the soul, like the invisible message along the telegraph wires.

The principles of the American Reformatory Prison System as here set forth are as yet incompletely practiced; but, more and more, men are learning that the eternal verities are within the acts and incidents of the daily life, that the public safety hinges upon a proper adjustment of individual and collective relativeness, and that the fulcrum of leverage is economic efficiency. This better view is fraught with promise for better public protection by means of rational reformation of offenders. 